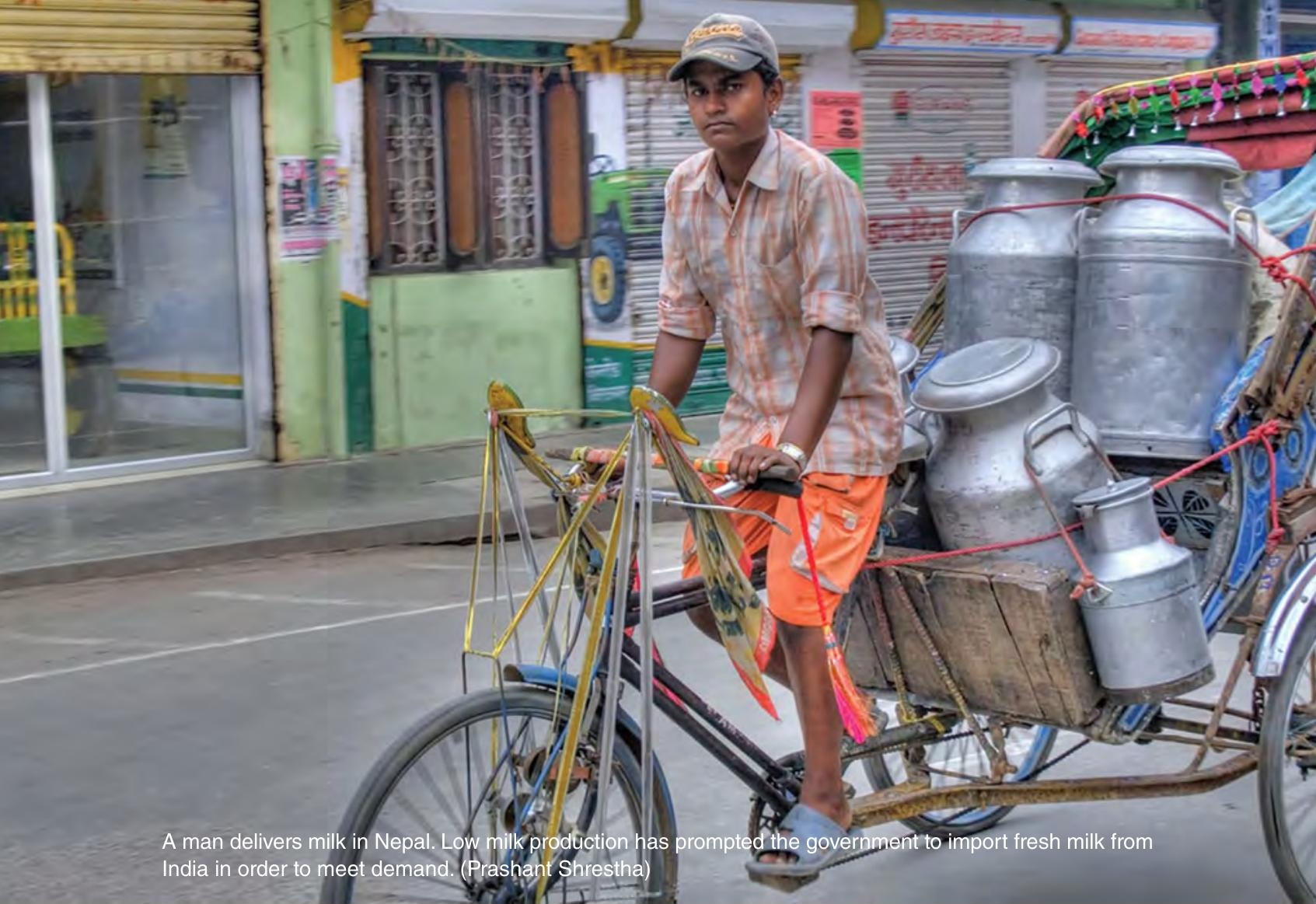

\title{
Seizing the Momentum to Reshape Agriculture for Nutrition
}

Shenggen Fan, Sivan Yosef* and Rajul Pandya-Lorch International Food Policy Research Institute (IFPRI), Washington, DC, USA

* Corresponding author: s.yosef@cgiar.org 


\section{Introduction}

The importance of agriculture to human welfare cannot be overstated. At its most basic level, agriculture, which includes not only plant cultivation but also animal husbandry, fisheries, and any activity occurring along the value chain from production to consumption, is the source of food and sustenance for the world's population. Ancient societies began cultivating and domesticating crops, livestock, and fish thousands of years ago. Key agricultural achievements such as irrigation, fertilizers, and selective breeding helped agriculture flourish in all parts of the globe under diverse, and at times barren, landscapes, enabling local populations to thrive. For much of history, humans have viewed agriculture as a tool of survival by way of providing enough calories.

This singular goal of agriculture, as a way of overcoming famine, carried over through the centuries and shaped the aims of perhaps the most famous achievement of modern agriculture, the Green Revolution, which focused on boosting agricultural production and productivity by investing in science and technology (to improve staple crops such as rice, wheat, and maize), irrigation, roads, and fertilizer production (Spielman and Pandya-Lorch, 2009). From 1960 to 1990 , this series of investments improved access to food and/or provided a critical source of income for approximately 1 billion people (Evenson et al., 2006).

But for all its achievements in the areas of production and productivity, and as a source of raw materials for industry, one critical contribution of agriculture has not received sufficient attention: nutrition. Food contains more than just calories. It delivers macronutrients, such as carbohydrates, fats, and proteins, as well as micronutrients, or vitamins and minerals. Humans need these micronutrients throughout their entire life cycle, though most critically from conception to 2 years of age, in order to achieve good growth and development. The taste and quality of highly nutritious food also affects people's demand for it. Beyond food, agriculture also provides a critical source of income for the world's poorest people, enabling them to purchase a wide array of healthy foods, healthcare, and education. It is linked to nutrition through myriad other ways, including by shaping gender roles, impacting food prices, and more. Despite these intractable links between agriculture and nutrition, the global community has historically been slow to get on board in expanding its vision of what agriculture can really do.

The consequences of inaction are staggeringly high. In 2017, 821 million people were undernourished (FAO et al., 2018). Stunting (being too short for one's age) affected more than one in five children, or 151 million children around the world, under 5 years of age (FAO et al., 2018). An additional 51 million children were affected by wasting, being too thin for their height. Among women of reproductive age, 33\% were affected by anemia (FAO et al., 2018). What is more, poor nutrition has lifelong and generations-long implications. Children who are undernourished at a young age start school later and complete fewer grade levels later in childhood (Alderman et al., 2006), and receive lower wages as adults (Behrman et al., 2004; Maluccio et al., 2009). Poorly nourished women give birth to poorly nourished children, perpetuating the cycle.

Agriculture feeds 7.6 billion people, and employs $69 \%$ of populations in low-income countries (FAO, 2011; ILO, 2017). It therefore has a vast potential to impact nutrition positively, a potential that has not been fully tapped. In response to this gap, individuals, organizations, and communities have begun to scale up their efforts to link agriculture and nutrition. This past decade has seen a flurry of activity to build up the evidence base on the ways in which agricultural and food systems can be redesigned and re-imagined for the benefit of nutrition.

This book seizes upon that momentum. It brings together research and programmatic advances, and policy developments at the national, regional, and global levels, during the past 5-10 years that have brought the two sectors closer together. It draws heavily from the International Food Policy Research Institute's (IFPRI) own research, as well as that of the growing agriculture-nutrition academic community, with supplementary insights from implementing and normative organizations. By highlighting the achievements - and setbacks - it offers lessons for those who want to engage in this work, whether within the policy arena, academia, or programming, and sets the stage for closing knowledge gaps and scaling up successes that can transform food systems and improve the nutrition of billions of people. 


\section{Conceptual Links Between Agriculture and Nutrition}

The authors in this volume introduce a range of conceptual frameworks, reflecting their different disciplines, to describe the relationship between agriculture and nutrition. Figure 1.1 shows these various relationships, as well as the feedback loop from individual nutrition outcomes to national economic growth, and the nutrition, health, and development of populations.

As noted above, agriculture is ultimately the source of food, delivering energy, macronutrients, and micronutrients essential for growth. Diversity in agricultural production is important along with total supply: areas with higher agricultural diversity produce more nutrients (Jessica Fanzo, see Chapter 4, this volume). Also, since many food producers consume what they produce, production diversity is strongly and positively associated with dietary diversity among young children (Kumar et al., 2015).
Agriculture is also a source of income for farmers that they can use to purchase healthy, diverse foods, as well as services that are integral to maintaining nutrition, including healthcare and education. Conversely, this income can be also used to purchase processed, unhealthy foods that can lead to overweight, obesity, and ill health (Olivier Ecker, see Chapter 8). One instrument that can affect the linkage between agriculture and nutrition, explored in Chapter 2 by Derek Headey and William Masters, is the relative cost of nutritious foods. The authors ponder whether different sources of calories have different levels of affordability. They compare the costliness of cereals, roots/tubers, fruits, vegetables, legumes, and animal-source foods in low-income versus wealthier countries. Furthermore, they probe the extent to which high prices hinder people from consuming certain foods.

A number of pathways from agriculture to nutrition consider the role of gender, as focused on by Hazel Malapit in Chapter 6. Participation

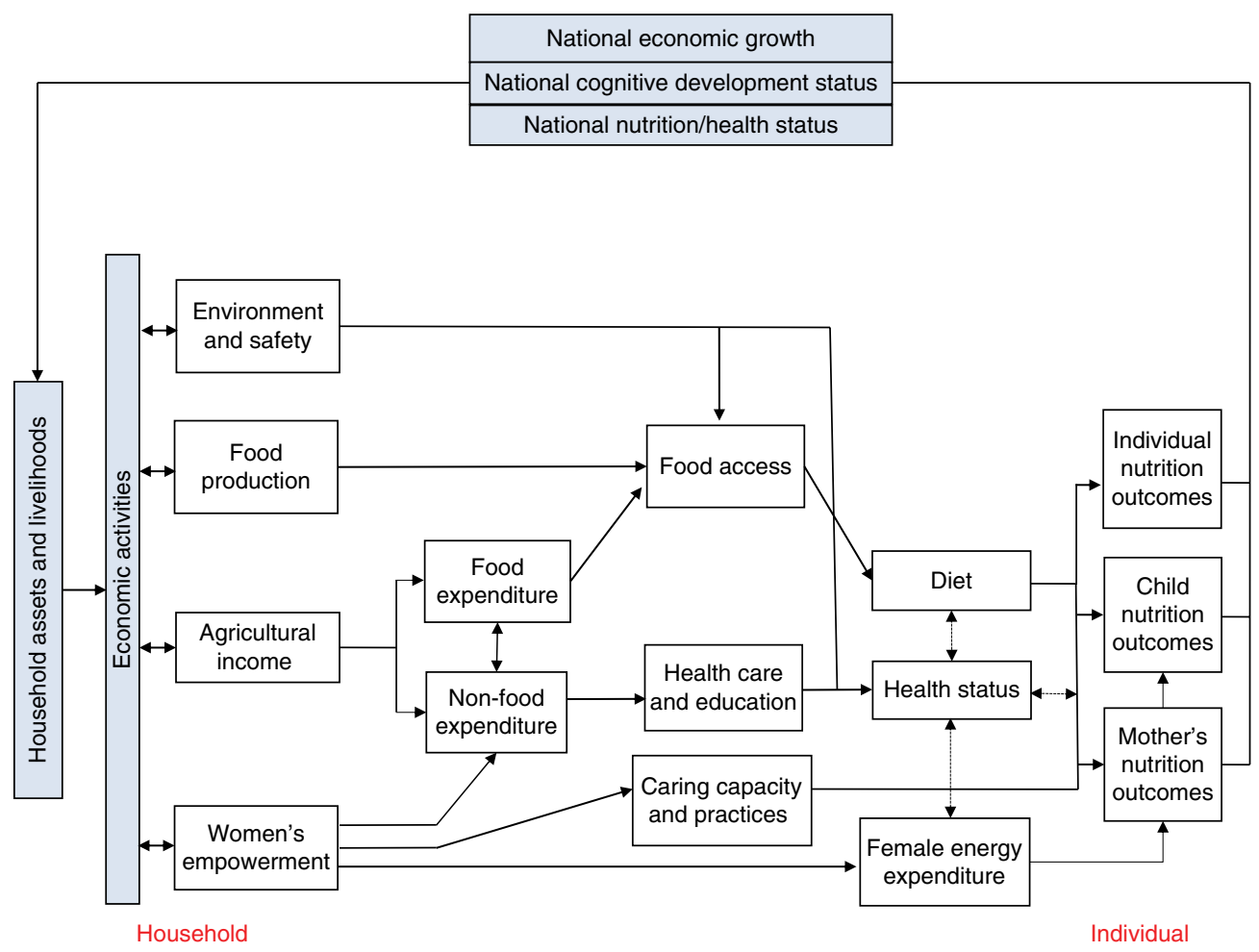

Fig. 1.1. Conceptual framework for agriculture-nutrition linkages. Adapted from Malapit (Chapter 6, this volume), Headey et al. (2011), Gillespie et al. (2012), Herforth and Harris (2014) and Kadiyala et al. (2014). 
in agriculture may give women increased access to and decision-making power over resources, such as income, and agricultural assets such as land and livestock, which in turn can increase their social status and empowerment to allocate food, health, and care within their households (Kadiyala et al., 2014). Women's time, and the trade-offs they make when they participate in agriculture, such as spending time on childcare (or not), can positively or negatively affect their own nutritional status and that of their children. Exposure to occupational health hazards, and excessive energy expenditure can also impact women's health and nutrition and the transmission of undernutrition to their future children (Kadiyala et al., 2014). Given these links, many interventions focus on women as beneficiaries, but should the aim to empower women actually expand more broadly to achieving gender equality within households? Malapit explores the recent research and program findings on this very question.

The impact of agricultural hazards goes beyond gender to affect producers' health through zoonotic and vector-borne diseases (since agriculture also includes animal husbandry), as well as consumer health through food safety. Agricultural practices may also lead to environmental degradation and subsequently poor health and nutrition, especially as many parts of the world face additional challenges like climate change (Daniel Raiten and Gerald Combs, see Chapter 7). The agricultural system may exacerbate inequality, such as when agricultural policies favor large farms, marginalizing smallholders; or contract farming results in unequal power dynamics (Dury et al., 2014).

One useful way of envisaging the links between agriculture and nutrition is by using a value-chain approach, which considers how nutrition can be retained in or added to food from production and processing to marketing and consumption. In Chapter 3, Summer Allen, Mar Maestre, and Aulo Gelli explore how value chains can build up the supply of nutritious food by improving agriculture-related infrastructure and processes, such as transportation and storage; or boost demand by, for example, promoting behavior change among consumers. The authors envision great potential for scaling up nutritiondriven value chains.

\section{A Nascent Field}

Although the agriculture-nutrition relationship was probed early on by some academics, their questions mostly focused on food security or calorie intake. As such, academic and policy interest in a broad range of agriculture-nutrition linkages is fairly recent. As described above, throughout most of the 20th century, the main focus of agricultural efforts was to address food shortages by increasing production (World Bank, 2014). Up until the 1980s, most economists still focused solely on strategies to produce more energy to meet consumer demand, under the assumption that nutrition did not play a role in consumer preferences.

The nutrition community had a similarly myopic view, focusing its efforts in the 1940s1960s on addressing protein deficiency. In the 1970s, nutritionists embraced multisectorality, advocating for the embedding of nutrition cells into larger government programs or divisions for agriculture or health within developing countries (Gillespie and Harris, 2016). This effort was largely abandoned a decade later due to lack of funding, capacity, political attention to nutrition, and poor project performance (World Bank, 2014).

In the 1990s, a small segment of the development community began to explore a wider agriculture-nutrition nexus, mainly through a focus on delivering micronutrients by consuming specific foods. In Chapter 5, Howarth Bouis, Amy Saltzman, and Ekin Birol take us through the journey of biofortification, the process of increasing the density of vitamins and minerals in a crop through plant breeding, transgenic techniques, or agronomic practices, which began in the early 1990s at CGIAR. These efforts, at the time anyway, still operated within a niche segment of the international development community. By now, nutrition professionals had shifted focus to delivering nutrition-specific interventions; agriculture professionals, on the other hand, continued on the path to improving productivity and market-led growth (World Bank, 2014). From 1973 onwards, for example, the World Bank carried out 40 agriculture projects that contained nutrition components, but nutrition was not a project development objective in any of these. 
The early 2010s seemed to signal a turning point. The power of the conceptual links between agriculture and nutrition was increasingly recognized, as were the shortcomings in their real-life application. The research community released several key reviews. Masset et al. (2011) concluded that there was a lack of empirical evidence on nutrition status outcomes of agricultural interventions, mainly due to poor study designs. Hawkes et al. (2012) undertook a mapping and gap analysis of 151 research projects, one-third of which were led by CGIAR, which revealed critical research gaps on such topics as value chains, agriculture's indirect effects on nutrition, and multisectoral governance and policy processes. Turner et al. (2013) confirmed these results.

In 2011, IFPRI held a global policy consultation on 'Leveraging Agriculture for Improving Nutrition and Health' in New Delhi, India. The consultation gave momentum to launch the CGIAR Research Program on Agriculture for $\mathrm{Nu}-$ trition and Health (A4NH), a large program which undertakes work on healthy food systems, biofortification, food safety, supportive policies and programs, and human health. It also prompted the Food and Agriculture Organization (FAO) of the United Nations (UN) to conduct an internal evaluation of its nutrition work, guided the UK's Department for International Development (DFID) to expand bilateral funding into the agriculture-nutrition nexus, and changed professional discourse, by "boosting the frequency of reference to cross-sector impacts on both nutrition and health' (Paarlberg, 2012). The research underlying this conference was compiled and released by Fan and Pandya-Lorch (2012).

This book focuses on the advances in agriculture and nutrition from this critical turning point, exploring research, policy, and programmatic advances during the past 5-10 years to review what has changed, and what has not.

\section{Recent Policy Developments}

At the global level, numerous policy platforms and mechanisms have been established during the past decade to address agriculture and nutrition both directly and indirectly. The Sustainable Development Goals (SDGs), set by the United Nations
General Assembly in 2015 as part of its '2030 Agenda', have an implicit focus on the intersection of agriculture and nutrition. SDG2 ("Zero Hunger'), which aims to 'end hunger, achieve food security and improved nutrition and promote sustainable agriculture', essentially combines agriculture and nutrition into one goal (Canavan et al., 2016). In 2012, the UN Sustainable Development Solutions Network was formed under the auspices of the UN Secretary-General and has since been carrying out agriculture-nutrition work through its Sustainable Agriculture \& Food Systems Thematic Network. The Network supports research and monitors progress toward SDG2, while also cooperating with national and local stakeholders to develop transformation pathways for SDG2.

In 2014, the International Conference on Nutrition 2 (ICN2) culminated in the release of the Rome Declaration on Nutrition, which recognized that food systems, inclusive of agriculture, need to contribute to nutritious, diverse, and balanced diets. It also noted that investing in agriculture, especially smallholders and family farmers, is essential to overcoming malnutrition. The work program of the UN Decade of Action on Nutrition, 2016-2025, provides a time-bound operational plan for achieving these aims and includes a focus on sustainable, resilient food systems for healthy diets and the support of cross-sectoral policies (WHO, 2017).

Climate and environmental change has been at the forefront of the global policy agenda for the past 5 years or so, and its links with agriculture and nutrition have been cited by some major documents and agreements. The 5th Assessment Report of the highly influential Intergovernmental Panel on Climate Change (IPCC), released in 2014, recognized the role of agriculture in contributing to malnutrition, noting an 'increased likelihood of under-nutrition resulting from diminished food production in poor regions (high confidence)'; and 'increased risks from foodand water-borne diseases (very high confidence) and vector-borne diseases (medium confidence)' (IPCC, 2014). The Paris Agreement of 2015 at the UN Climate Change Conference of Parties (COP 21) referred to food security and food production, but not agriculture. Negotiations for the 2017 UN Climate Change Conference (COP23) in Bonn, Germany, broke a deadlock on agriculture with parties agreeing to discuss issues such as soil fertility, adaptation and resilience, and 
livestock management, but the issue of nutrition was notably absent. However, research and development organizations remained prominent at the sidelines of COP23, holding side events on sustainable food systems and health (UNSCN et al., 2015). Daniel Raiten and Gerald Combs (Chapter 7) raise the question of whether we need to start using nutrition ecology as a way of understanding the complex interactions among agriculture, nutrition, and climate and environmental change on land, water, and air quality; weather; food safety; and human use patterns. Can ecological approaches, which acknowledge that food systems are affected by multiple factors, help us design locally relevant interventions that ensure both nutrition and resilience to climate change?

There has also been progress within regional policy circles, most prominently in Africa. In 2011-2013, the African Union Commission and New Partnership for Africa's Development (NEPAD) engaged 600 stakeholders from the Comprehensive Africa Agriculture Development Programme (CAADP) in a Nutrition Capacity Development Process. The process created context-specific roadmaps for 48 countries that lay out how CAADP investment plans can integrate nutrition within their objectives, targeting, implementation, communication, and evaluation. Phase II (2014 onwards, facilitated by NEPAD and FAO) focuses on improving nutrition governance at the regional level, leveraging resources for capacity building within agriculture-nutrition activities, and monitoring and evaluation (FAO, 2015).

In 2012, the G8 (Group of Eight intergovernmental political forum, 1997-2014) launched the New Alliance for Food Security and Nutrition initiative to draw the private sector into positively transforming agriculture and food production in Africa. By mid-2015, the ten participating African governments had made progress on or completed $92 \%$ of their policy commitments, which include promoting policies that "can affect nutrition, including biofortification, fortification, nutrition policies, and malnutrition treatment' (New Alliance, 2015).

Many donors have also increased their funding for nutrition-sensitive sectors such as agriculture. During the past decade, DFID has boosted its funding of nutrition-sensitive initiatives from approximately US\$300 million in 2010 to US\$900 million in 2015 (Development
Initiatives, 2017). During 2010-2015, agriculture, food security, and other social services represented $21 \%$ of DFID's nutrition-sensitive aid (MQSUN, 2017). The US government launched Feed the Future in 2010, which seeks to drive economic and agricultural development in low-income countries. The majority of the USA's international nutrition efforts are carried out in Feed the Future's 19 focus countries; the program received US $\$ 11$ billion in 2010-2014 (Donor Tracker, 2018). USAID's Multi-Sectoral Nutrition Strategy 2014-2025 highlights the links between nutrition and supporting sectors such as agriculture (Donor Tracker, 2018). The 11 major global donors to nutrition (excluding CIFF and the World Bank, for which data was not complete) contributed US $\$ 5.45$ billion to nutrition-sensitive sectors in 2015, up from US $\$ 2.97$ billion in 2012; the specific allocation to agriculture was not available (Development Initiatives, 2017).

At the country level, numerous national policies have been released with the aim of bringing the agriculture and nutrition sectors closer together. Several countries have mainstreamed nutrition into their agricultural plans and strategies. Uganda's National Agriculture Policy of 2013 emphasizes food and nutrition security within its first objective, including supporting local governments in ensuring household nutrition, and promoting the production and consumption of nutritious foods, including indigenous foods (Republic of Uganda, 2013). Similarly, nutrition was incorporated for the first time into Guinea's 2011-2015 agricultural investment strategy; and Burundi's 2012-2017 National Agricultural Sector Investment Plan includes a sub-program for ensuring nutrition for vulnerable populations (SUN, 2015).

Cross-sectoral integration has been multidirectional, with some countries integrating agriculture into nutrition plans. As Kevin Chen and Zimeiyi Wang report in Chapter 19, China's National Nutrition Plan aims to produce nutritious and safe agricultural products and roll out national-level demonstration sites for researching nutritious staples and how to safeguard nutrition along the food supply chain. This is a welcome development alongside the inclusion of nutrition in the country's No. 1 Central Document, which has customarily focused exclusively on agricultural and rural development. But, as 
the authors investigate, does China's increased attention to agriculture-nutrition links carry over into programs and interventions, and whose nutrition has been left behind in the economic boom of the past three decades?

In Vietnam, the Ministry of Agriculture and Rural Development is tasked with helping carry out various components of the National Nutrition Strategy 2011-2020, including micronutrient deficiency control, nutrition surveillance, and nutrition security during emergencies (Government of Vietnam, 2012). Peru's Incluir para Crecer (Include to Grow) strategy, which focuses on the nutrition and development of the country's rural poor, delegates key activities to the Ministry of Agriculture; the ministry was also responsible for coordinating the National Strategy for Food and Nutrition Security (ACF, 2013).

Still other countries have focused their efforts on forming cross-sectoral mechanisms. To implement its National Food and Nutrition Policy and National Food and Nutrition Strategic Plan, the Rwandan government set up a steering committee with the Ministries of Health, Agriculture and Animal Resources, and with local government acting as co-chairs (Compact2025, 2016). Similarly, Laos established a multisectoral nutrition committee to coordinate actions and investments in nutrition; the committee is chaired by the vice minister of Health and co-chaired by the vice ministers of Agriculture and Forestry, of Education and Sport, and of Planning and Investment (SUN, 2015).

In Chapter 15, Akhter Ahmed and Julie Ghostlaw explore the agriculture-nutrition progress in Bangladesh, which has enjoyed one of the fastest prolonged declines in child undernutrition in the world, credited to households' accumulation of wealth; access to education; community-based health services; sanitation; and lastly, rapid growth in agriculture (Shahan and Jahan, 2017). In 2015, the government of Bangladesh passed the National Nutrition Policy, which, among other actions, uses multisectoral coordination to promote dietary diversity through nutrition-sensitive agriculture, including behavior change communication and food fortification (Shahan and Jahan, 2017). Ahmed and Ghostlaw ponder the role of market-induced risks for the production of crops other than rice, raising the question of how hard it actually is to diversify production into more nutrient-dense crops.
In Chapter 16, Anne Bossuyt describes how the development of Ethiopia's revised National Nutrition Program (2013-2015) closely involved the agriculture sector, which will help coordinate the program and support it by increasing the production and consumption of nutritious foods, expanding research, and integrating nutrition and gender into its own agricultural programs. The country's second National Nutrition program (2016-2020) includes strategic objectives and operational guidelines for each sector, as well as a costed action plan. Equally as consequential, the country has launched the first National Nutrition-Sensitive Agriculture Strategy, which calls on the sector to address malnutrition through production and productivity, agricultural income, and women's empowerment, and also mainstreams nutrition into various agriculture sub-strategies.

Other countries have taken innovative policy approaches to linking agriculture and nutrition. Brazil, for example, passed legislation in 2009 requiring 30\% of the budget of the national school feeding program to be allocated toward purchasing food from family and local rural enterprises. Although school feeding programs are implemented in nearly all countries around the world, Brazil became the first country to legislate a link between agricultural production and school feeding (Hawkes et al., 2016).

At the national level, safety nets (including conditional transfers, school meals, public works) have also proliferated during the past two decades but, as Daniel Gilligan describes in Chapter 10, social protection programs that provide complementary components in both agriculture and nutrition are scarce. Gilligan asks whether programs combining transfers with agricultural investment and behavior change communication oriented to nutrition could be effective, and determines that the right design of such an integrated program depends on policy priorities and local context.

Still, significant challenges remain. In Chapter 17, Prabhu Pingali and Mathew Abraham detail India's great strides in food security, including its passage of the National Food Security Act in 2013, which gives access to subsidized food grains for $75 \%$ of rural residents and $50 \%$ of urban residents. The Act, however, focuses on staple grains and does not attempt to address micronutrient deficiencies or protein energy 
malnutrition, though it does have nutritional security as an explicit aim. Pingali and Abraham point to other policies in India that show promise in better multisectoral integration, including the newly formulated (2016) National Nutrition Strategy and the draft Policy for Women, but also lament major disconnects between the two sectors. Their proposal for closing these gaps involves borrowing elements from a food-systems approach, such as looking at nutrition needs within households, not just across them, and devising ways to help especially vulnerable members.

The focus of Indian agricultural policies on grain production is similar to that of Malawi, which is characterized by policies and programs centered on maize. In Chapter 18, Noora-Lisa Aberman describes a recent shift (driven by donors, program implementers, and researchers) in pushing Malawi's agriculture sector to address malnutrition. This shift is apparent in policy statements and documents but not yet within nutrition-sensitive programming, and the author identifies some 'low-hanging fruit' or promising approaches that the agriculture sector could take to increase multisector coordination.

As countries turn their attention to malnutrition, many struggle with significant demographic shifts, such as urbanization, which (together with rising incomes) have given way to rising levels of overweight and obesity. In Chapter 8, Olivier Ecker describes how economic growth, a decades-long decline in the price of foods (such as cereals, beef, and milk), and trade liberalization have all played a part in this new nutrition challenge. Ecker explores the role of agriculture, and more specifically distortion to agricultural incentives, in the growing obesity epidemic in poor countries.

\section{Building up the Evidence Base}

For all the policy shifts around the agriculture and nutrition nexus, what does the latest evidence conclude regarding these links? Research during the past 5 years has found that the evidence base regarding the contribution of agriculture to nutrition remains weak (Marie Ruel, see Chapter 9). Numerous studies (Webb Girard et al., 2012; Ruel and Alderman, 2013; Webb and Kennedy, 2014; Ruel et al., 2017) have confirmed the findings of Masset et al. released in
2011 (described above): the majority of the evidence on agriculture-nutrition links suffers from poorly designed studies and research methodologies. These same conclusions have been drawn from regional-level reviews as well. The findings of the research consortium Leveraging Agriculture for Nutrition in South Asia (LANSA) concluded that the evidence base in South Asia was scant, especially lacking data on the role of women in agriculture and nutrition (Gillespie and van den Bold, 2017). In India, however, agriculture was found to have affected the dietary patterns of households, food prices, and incomes and expenditures. The Leveraging Agriculture for Nutrition in East Africa (LANEA) project released similar findings for East Africa: most research in the region focuses on agriculture as a source of food, and there is especially weak evidence on women's role in agriculture (Gillespie and van den Bold, 2017).

However, this conclusion belies a wealth of knowledge on the agriculture-nutrition nexus that has brought awareness and political urgency to the topic in recent years. In 2008, The Lancet released a series on maternal and child undernutrition, which helped lead to the founding of the Scaling Up Nutrition (SUN) Movement in 2010. In 2013, The Lancet released a second series on nutrition, marking the first time that nutrition-sensitive interventions (including agriculture) were analyzed. Paper 3 of the series by Ruel and Alderman (2013) focused on micro-studies showing, once again, a lack of evidence that agricultural programs affect nutrition, with the exception of vitamin A from biofortified orange sweet potatoes. However, the paper also noted that program designs have improved vastly during the past decade and are increasingly being based on strong program theory and clear impact pathways. These sound designs are charting the way for high-quality program evaluations within the next decade that could better inform agricultural and nutrition investments (Ruel and Alderman, 2013).

There have been other high-level research developments. In 2016, the EAT-Lancet Commission on Healthy Diets from Sustainable Food Systems was launched in Stockholm with the aim of achieving scientific consensus on what healthy diets entail. In early 2019, the Commission will release its final recommendations on legislative and private-sector actions that can be taken to 
accelerate the nutrition-sensitive transformation of the food system, with explicit recognition of the environmental, health, and nutrition challenges associated with the current agricultural system. Other key publications have included new journals (such as the African Journal of Food, Agriculture, Nutrition, and Development), journal special issues (Food Security) and seminal reports (United Nations System Standing Committee on Nutrition's SCN News and the FAO's 2013 State of Food and Agriculture Report, to name a few).

Biofortification continues to stand out as a success that is increasingly backed by solid evidence. The Copenhagen Consensus ranked biofortification as one of the highest value-for-money investments for economic development (Hoddinott et al., 2012). Evaluations carried out in Uganda and Mozambique found high adoption rates among farmers, higher inclusion of vitamin A in diets of women/children, and, in Uganda, improvement of children's vitamin A status (Hotz et al., 2012a, b). Additionally, an integrated agriculture (biofortified sweet potato) and nutrition intervention reduced the prevalence of vitamin A deficiency among children by $15 \%$ (Low et al., 2007). In Chapter 5, Bouis, Saltzman, and Birol explore how biofortification could reach 1 billion people by the year 2030 .

The chapters in this volume detail the latest research to come out on agriculture-nutrition links. In the meantime, the research community continues to move forward. Various major research initiatives have emerged through the Leverhulme Centre for Integrative Research on Agriculture and Health; IFPRI projects such as Tackling the Agriculture Nutrition Disconnect in India; the Tata-Cornell Agriculture and Nutrition Initiative; and the previously mentioned $\mathrm{A} 4 \mathrm{NH}$ CGIAR Research Program. A number of organizations and projects, such as the International Dietary Expansion project, have improved the collection and sharing of data on agriculture and nutrition (INDDEX, 2018). Others, such as Feed the Future, are piloting ways of measuring the level of integration of agriculture-nutrition interventions (Masters et al., 2014). These efforts are crucial and reflect a greater interest in data, especially big data, during the past few years. In Chapter 14, Ruthie Musker asks whether big data is just hype, or whether it truly has the power to 'disrupt' agricultural systems for the benefit of nutrition. As Musker describes the many ways in which data that is analyzed and layered together with other datasets can be used, from helping farmers prepare for weather patterns or sending decision makers early warnings about imminent famine, the answer seems to be the latter. Musker calls for greater efforts to ensure that data is responsibly collected and used, freely accessible, and easily understood by non-researchers, such as policymakers and program implementers.

Research is only one piece of the agriculturenutrition puzzle: the research needs to be translated into actual programming on the ground. Multisectoral interventions that can diversify agricultural production, increase incomes and spending on healthy diets, water, sanitation, health and education, improve access to markets, positively change behaviors, and work toward gender equality are key in closing the agriculture-nutrition gap. During the past decade, the trend among non-profit international non-governmental organizations (NGOs) has been:

... towards greater integration across sectors. Integrated programs are giving higher priority to nutrition, and new program emphases have emerged on water, sanitation and hygiene, on value chains linking agriculture to markets, and on intra-household dynamics and gender roles.

(TANGO International, 2015)

Much of this integration has occurred within large institutions. In 2013, for example, FAO released a synthesis of guiding principles on agriculture programming for nutrition, which compiled all of the guidance, institutional strategies and other publications released by international development organizations on how to help agriculture positively impact nutrition (FAO, 2013). And, as previously mentioned, USAID's Feed the Future has been implementing agriculture-nutrition in 19 countries.

But advances are being made within smaller organizations as well. A vast majority of agriculture-nutrition interventions are now using dietary diversity scores to evaluate their impact; this was not the case in 2008 when most simply measured the consumption of specific foods. Women's dietary diversity scores are also being used, as is the Women's Empowerment in Agriculture Index, thus filling a critical gap (Herforth and Ballard, 2016). Agriculture-nutrition linkages have also begun to be integrated into many organizations' operational strategies. 
A number of best practices, lessons, and tools have also emerged. The Integrating Gender and Nutrition within Agricultural Extension Services project and Global Forum for Rural Advisory Services released 'Global Good Practice Notes' on gender and nutrition in the context of agriculture extension, advising extension officers to adapt their nutrition messages to low literacy levels, make cost-benefit analyses easily understandable to smallholders, and personalize messages to local dietary patterns (KachelriessMatthess et al., 2016). FAO released its checklist and program formulation guidance note on 'Designing Nutrition-Sensitive Agriculture Investments', and Action Contre la Faim (ACF, 2018) released a series of case studies on innovative nutrition-sensitive interventions. These are just a few examples of a growing number of resources available to program designers and implementers wishing to integrate nutrition into their agricultural initiatives more effectively.

Although there are still significant evidence gaps, the role of the private sector in nutrition has also emerged as a topic of interest in recent years, as reported by Lawrence Haddad in Chapter 11. Haddad asserts that businesses have the power to improve nutrition outcomes, but whether this goal is realized depends on whether they or governments can boost demand for nutritious products through behavior change communication and price policies; whether supply of healthy foods can be boosted through innovations such as fortification, technical support, and tax incentives; and whether business practices that harm nutrition and health can be effectively regulated. Despite the fact that the big businesses can reshape entire food systems in a relatively short period of time, as evidenced by their role in the nutrition transition in many low-income countries, there are still few rigorous evaluations of the impact of private-sector engagement in nutrition - a gap that is bound to be closed in the coming years as countries continue to urbanize and markets grow (Hoddinott et al., 2016).

\section{Getting the Word Out and Building Capacity at All Levels}

Malnutrition is often described as an invisible issue. People living in countries with high rates of child stunting, overweight, and/or obesity often view these conditions as the norm and not requiring action. Malnutrition is also not infectious, thus further reducing its priority level for policymakers (Gillespie et al., 2016). Political attention to nutrition, therefore, must be built up through effective communications, advocacy, and investment in capacity. The field of nutrition has become considerably more prominent in recent years through such initiatives as the SUN movement, and the subset of agriculturenutrition is slowly gaining visibility too.

Perhaps the largest communications feat for the agriculture-nutrition community was the announcement that the group of researchers who pioneered biofortification had won the 2016 World Food Prize (see Chapter 5 on biofortification, co-authored by one of the winners, Howarth Bouis). Two years later, HarvestPlus was selected as one of four finalists in the MacArthur Foundation's 100\&Change competition, which identifies ambitious solutions for critical challenges of our time. These two achievements brought high visibility to the field. Also in 2018, Lawrence Haddad and David Nabarro won the World Food Prize for their role in elevating maternal and child undernutrition within the global and national development agendas, drawing further attention to these vital issues.

The agriculture-nutrition community has also made strides in communicating its messages to external lay audiences through a proliferation of non-technical keystone publications, such as the Global Nutrition Report (Development Initiatives, 2017) or key reports released by the independent Global Panel on Agriculture and Food Systems for Nutrition (based in London), and by the FAO's High Level Panel of Experts (HLPE) on Food Security and Nutrition; and the UNSCN. The language or 'buzz words' used to describe agriculture-nutrition links is also evolving, with the term 'nutrition-driven agriculture' being used more and more. While this shift may seem like an issue of semantics, it also represents a more forceful integration of nutrition into agricultural interventions with the message that agriculture should have nutrition as a primary, not peripheral, aim.

Other communication tools have emerged. Online communities have brought experts together for informal debates and even produced key publications, such as the Agriculture-Nutrition 
(Ag2Nut) Community of Practice's release of its Guiding Principles for Improving Nutrition through Agriculture in 2013. New tools for communicating knowledge have included blogs, webinars, and even a community-led video approach from SPRING (Strengthening Partnerships, Results, and Innovations in Nutrition Globally, sponsored by USAID) and Digital Green. Major meetings, such as the Integrated Nutrition Conference hosted by Catholic Relief Services and $\mathrm{A} 4 \mathrm{NH}$ and the annual conference of the Leverhulme Center for Integrative Research on Agriculture and Health (LCIRAH), have included the participation of not only researchers but also program implementers and policymakers. Professional gatherings are also becoming more interdisciplinary. The Milan Conference of the International Association of Agricultural Economists, for example, integrated nutritionists for the first time ever in 2015.

As Suresh Chandra Babu describes in Chapter 13, universities, donors, and governments have also joined hands to build up capacity at individual, institutional, and system levels to carry out research in agriculture-nutrition and design agricultural projects with clear impact pathways to nutrition. Various universities and organizations have integrated nutrition into curricula and are beginning to assess nutrition-sensitive agriculture competencies among their students. UNICEF India developed a nutrition curriculum for mid-level agriculture professionals, while USAID/Malawi integrated nutrition curricula into medical colleges, and agriculture and natural resources universities, modeled after similar programs in South Africa and the USA. Governments have also begun providing nutrition training to agricultural extension agents. Ethiopia's Ministry of Agriculture and Natural Resources and Ministry of Education are collaborating on integrating nutrition into mid-level agriculture curricula through the development of core competencies and standards-based courses (FANTA, 2016). Babu asks what type of capacitybuilding efforts will be required to scale up the agriculture-nutrition initiatives being pioneered around the world.

Academic organizations have also come on board: the IMMANA (Innovative Methods and Metrics for Agriculture and Nutrition Actions) initiative, for example, provides competitive research grants and postdoctoral fellowships for research in agriculture-nutrition, and also organizes the Agriculture, Nutrition, and Health Academy, which hosts physical and online courses and resources on relevant topics.

Research organizations such as the London School of Hygiene and Tropical Medicine (LSHTM) and implementing organizations such as CARE (based in Atlanta, Georgia) and Catholic Relief Services (CRS, in Baltimore, Maryland) have hired staff with cross-disciplinary competencies to carry out their work. The University of Michigan hired a cluster of crossdisciplinary professors to develop a food systems track, while Johns Hopkins University in Baltimore created a postdoctoral fellowship in the area of food, agriculture, and nutrition ethics.

\section{Strengthening the Evidence and Moving to Action}

The past decade has seen significant advances in linking agriculture and nutrition, within policy, research, program design and implementation. At the same time, the knowledge gaps are vast. In Chapter 9, Ruel points out that the evidence on how agriculture can positively impact nutrition is still scant. She summarizes the latest findings, which show that agricultural programs with an orientation to production diversity, biofortification, dairy, and small livestock rearing can improve production and consumption of these specific commodities. At times, these interventions may even lead to increased household, maternal, and child dietary diversity. But with a few exceptions (such as biofortified sweet potatoes), agricultural interventions are still unable to impact child stunting, underweight, or wasting. Ruel calls for more and higher-quality evidence, based on strong research methodologies, that can elucidate how to enhance the impacts of agriculture on nutrition outcomes, and furthermore, to analyze the cost-effectiveness of various integrated interventions.

The shortcomings in bringing agriculture and nutrition together are reflected not only within the evidence gaps, but also within program design. Many nutrition-sensitive agricultural interventions do not take into account that production and consumption decisions within households are often separate, and that, except 
for income, farming households' production decisions may not directly affect their consumption. Program designs that treat households as both consumers and producers may therefore find more success. For example, homestead food production interventions seem to be more effective in impacting nutrition when they integrate nutrition education, perhaps because they acknowledge that their beneficiaries play both roles in the food system. This approach needs to be probed further.

Indeed, topics that are critical to agriculture and nutrition have still not been explored. The contribution of value chains to nutrition, for example, especially chains centered on micronutrient-rich, perishable foods such as fruits, vegetables, dairy, and animal-source products, is a critically understudied issue (see Chapter 3 ). As Fanzo describes in Chapter 4, more evidence is also needed on how to manage biodiversity, comprising millions of species of plants, animals, and other kingdoms that sustain life and also support ecosystem services that are essential to agriculture, such as nutrient cycling, pest management, and pollination. Fanzo identifies critical questions, such as how can we design smart biodiversity systems that prevent biodiversity loss while also promoting nutrition, and how can value be added to nutritious crops that are at the edge of extinction, to build up demand for them once again?

As argued in Chapter 12 by Stuart Gillespie and Nicholas Nisbett, creating an enabling environment for agriculture and nutrition is perhaps the most critical action that can be undertaken to address the multiple drivers of malnutrition. These types of environment are characterized by the effective communication of knowledge, data, and evidence; political commitment; good governance; and leadership, capacity, and financing. Gillespie and Nisbett advocate that governance and leadership should not be separated: it takes leadership to implement effective systems of governance that can lead to healthier, more equitable, and more sustainable food system outcomes. They point to clear research gaps on the intersection of nutrition and political contexts, governance systems, and styles and type of leadership. Knowledge about how competing interests and trade-offs are weighed in designing integrated agriculturenutrition policies, lessons in fostering leaders and advocates for nutrition within the agricultural sector, and how commitments can be secured to establish a stronger research and programmatic evidence base can ensure success in the future.

The agriculture-nutrition community has generated more than enough momentum during the past decade to address these knowledge gaps. Nor should these knowledge gaps be an excuse for lack of action. Policy guidance does not necessarily always need to be based on goldstandard study designs (such as randomized controlled trials, which are notoriously difficult to apply to the food system), as long as the evidence base continues to grow in incremental ways (Pinstrup-Andersen, 2013).

Indeed, it is an exciting time to be a student or professional in this field. Every day, more evidence on the agriculture-nutrition nexus is being generated. Leaders in these sectors are stepping up to advocate for nutrition and multisectorality. Capacity is being built up within people and institutions to carry out this work. These critical efforts will exponentially improve the design and implementation of interventions and policies, helping reshape the agricultural and food system, and achieve better nutrition for the world's most vulnerable people.

\section{References}

ACF (2013) Reconciling agriculture and nutrition: case study on agricultural policies and nutrition in Peru. ACF-International Case Study. Action Contre la Faim (ACF), Paris.

ACF (2018) ACF strategies for agricultural interventions. Action Contre la Faim, Paris. Available at: https:// www.actionagainsthunger.org/media/publications?page=8 (accessed 4 April 2018) and https://www. actioncontrelafaim.org/en/publication/acf-strategy-for-agricultural-interventions/ (accessed 10 April 2018).

Alderman, H., Hoddinott, J. and Kinsey, B. (2006) Long-term consequences of early childhood malnutrition. Oxford Economic Papers 58(3), 450-474. 
Behrman, J., Alderman, H. and Hoddinott, J. (2004) Hunger and Malnutrition. Copenhagen Consensus Challenge Paper. Copenhagen Consensus, Copenhagen.

Canavan, C.R., Graybill, L., Fawzi, W. and Kinabo, J. (2016) The SDGs will require integrated agriculture, nutrition and health at the community level. Food and Nutrition Bulletin 37(1), 112-115.

Compact2025 (2016) Rwanda: Ending Hunger and Undernutrition, Challenges and Opportunities. Scoping report for roundtable discussion. International Food Policy Research Institute (IFPRI), Washington, DC.

Development Initiatives (2017) Global Nutrition Report 2017: Nourishing the SDGs. Development Initiatives, Bristol, UK.

Donor Tracker (2018) United States Nutrition, Donor Tracker. Available at: https://donortracker.org/unitedstates/nutrition (accessed 9 April, 2018).

Dury, S., Alpha, A. and Bichard, A. (2014) What Risks Do Agricultural Interventions Entail for Nutrition? Working Paper MOISA 2014-3, presented to Action Contre la Faim (ACF), Paris, 10 Feburary 2014. UMR MOISA (Unité Mixte de Récherche: Marchés, organisations, institutions et stratégies d'acteurs CIHEAM-IAMM, CIRAD, INRA, Montpellier SupAgro), Montpellier, France.

Evenson, R.E., Msangi, S., Sulser, T.B. and Rosegrant, M.W. (2006) Green Revolution Counterfactuals. Paper presented at the annual meeting of the American Agricultural Economics Association, July 23-26, Long Beach, California.

Fan, S. and Pandya-Lorch, R. (2012) Reshaping Agriculture for Nutrition and Health. International Food Policy Research Institute (IFPRI), Washington, DC.

FANTA (2016) Multi-Sectoral Nutrition Global Learning and Evidence Exchange East and Southern Africa Meeting Highlights, March 8-10, 2016. Food and Nutrition Technical Assistance III Project. FHI 360/ FANTA, Washington, DC.

FAO (2011) The State of Food and Agriculture. Women in Agriculture. Closing the Gender Gap for Development. Food and Agriculture Organization, Rome.

FAO (2013) Synthesis of Guiding Principles on Agriculture Programming for Nutrition. Food and Agriculture Organization, Rome.

FAO (2015) Integrating nutrition in CAADP investment plans. Available at: http://www.fao.org/nutrition/ policies-programmes/capacity-development/caadp/nutrition-task-force/en/ (accessed 9 April 2018).

FAO, IFAD, UNICEF, WFP and WHO (2018) The State of Food Security and Nutrition in the World 2018. Building climate resilience for food security and nutrition. Food and Agriculture Organization of the United Nations, Rome.

Gillespie, S. and Harris, J. (2016) How nutrition improves: half a century of understanding and responding to the problem of malnutrition. In: Gillespie, S., Hodge, J., Yosef, S. and Pandya-Lorch, R. (eds) Nourishing Millions: Stories of Change in Nutrition. International Food Policy Research Institute (IFPRI), Washington, DC, pp. 1-13.

Gillespie, S. and van den Bold, M. (2017) Agriculture, food systems, and nutrition: meeting the challenge. Global Challenges 1(3).

Gillespie, S., Harris, J. and Kadiyala, S. (2012) The Agriculture-Nutrition Disconnect in India: What Do We Know? International Food Policy Research Institute (IFPRI), Washington, DC.

Gillespie, S., Hodge, J., Pandya-Lorch, R., White, J. and Yosef, S. (2016) New horizons: nutrition in the 21st century. In: Gillespie, S., Hodge, J., Yosef, S. and Pandya-Lorch, R. (eds) Nourishing Millions: Stories of Change in Nutrition. International Food Policy Research Institute (IFPRI), Washington, DC, pp. $175-179$.

Government of Vietnam (2012) National Nutrition Strategy for 2011-2020, with a Vision toward 2030. No: 226/QD-TTg. Government of Vietnam, Hanoi.

Hawkes, C., Turner, R. and Waage, J. (2012) Current and Planned Research on Agriculture for Improved Nutrition: a Mapping and a Gap Analysis. A report for DFID. Leverhulme Centre for Integrative Research on Agriculture and Health (LCIRAH), London.

Hawkes, C., Gerken Brazil, B., Rugani Riberio de Castro, I. and Constante Jaime, P. (2016) How to engage across sectors: lessons from agriculture and nutrition in the Brazilian School Feeding Program. Revista de Saúde Pública 50, 40-47.

Headey, D., Chiu, A. and Kadiyala, S. (2011) Agriculture's Role in the Indian Enigma: Help or Hindrance to the Undernutrition Crisis? IFPRI Discussion Paper 01085. International Food Policy Research Institute (IFPRI), Washington, DC.

Herforth, A. and Ballard, T.J. (2016) Nutrition indicators in agriculture projects: current measurement, priorities, and gaps. Global Food Security 10, 1-10. 
Herforth, A. and Harris, J. (2014) Understanding and Applying Primary Pathways and Principles. Brief \#1. Improving Nutrition through Agriculture Technical Brief Series. USAID/Strengthening Partnerships, Results, and Innovations in Nutrition Globally (SPRING) Project, Arlington, Virginia.

Hoddinott, J., Rosegrant, M. and Torero, M. (2012) Investments to Reduce Hunger and Undernutrition. Paper prepared for 2012 Global Copenhagen Consensus. Copenhagen Consensus Center, Tewksbury, Massachusetts.

Hoddinott, J., Gillespie, S. and Yosef, S. (2016) Public-private partnerships and undernutrition: examples and future prospects. In: Biesalski, H. and Black, R. (eds) Hidden Hunger. Malnutrition and the First 1,000 Days of Life: Causes, Consequences and Solutions. Karger, Basel, pp. 233-238.

Hotz, C., Loech, I. and Lubowa, A (2012a) Introduction of $\beta$-carotene-rich orange sweet potato in rural Uganda resulted in increased vitamin $A$ intakes among children and women and improved vitamin $A$ status among children. Journal of Nutrition 142, 1871-1880.

Hotz, C., Loech, I. and De Brauw, A. (2012b) A large-scale intervention to introduce orange sweet potato in rural Mozambique increases vitamin A intakes among children and women. British Journal of Nutrition 108, 163-176.

INDDEX (2018) Our Approach. International Dietary Data Expansion, Tufts University, Medford, Massachusetts. Available at: https://inddex.nutrition.tufts.edu/project-overview (accessed 10 April 2018).

ILO (2017) Employment by sector - ILO modelled estimates, November 2017. International Labour Organization, Geneva. Available at: http://www.ilo.org/ilostat (accessed 23 May 2018).

IPCC (2014) Climate Change 2014: Synthesis Report. Contribution of Working Groups I, II and III to the Fifth Assessment Report of the Intergovernmental Panel on Climate Change (eds Core Writing Team, R.K. Pachauri and L.A. Meyer). IPCC, Geneva, Switzerland.

Kachelriess-Matthess, S., Matthess, A., Stancher, A., Asare, B. and Afoakwa, E.O. (2016) Promoting Nutrition-sensitive Extension Advisory Services. Note 25. GFRAS Good Practice Notes for Extension and Advisory Services. Global Forum of Rural Advisory Services, Lausanne, Switzerland.

Kadiyala, S., Harris, J., Headey, D. and Gillespie, S. (2014) Agriculture and nutrition in India: mapping evidence to pathways. Annals of the New York Academy of Sciences 1331(1), 43-56.

Kumar, N., Harris, J. and Rawat, R. (2015) If they grow it, will they eat and grow? Evidence from Zambia on agricultural diversity and child undernutrition. The Journal of Development Studies 51(8) 1060-1077.

Low, J.W., Arimond, N., Osman, N., Cunguara, B., Zano, F. and Tschirley, D. (2007) A food-based approach to introducing orange-fleshed sweet potatoes increased vitamin $A$ intake and serum retinol concentrations in young children in rural Mozambique. Journal of Nutrition 137, 1320-1327.

Maluccio, J.A., Hoddinott, J.F., Behrman, J.R., Martorell, R., Quisumbing, A.R. and Stein, A.D. (2009) The impact of improving nutrition during early childhood on education among Guatemalan Adults. Economic Journal 119(537), 734-763.

Masset, E., Haddad, L., Cornelius, A. and Isaza-Castro, J. (2011) A Systematic Review of Agricultural Interventions that Aim to Improve Nutritional Status of Children. EPPI-Centre, Social Science Research Unit, Institute of Education, University of London, London.

Masters, W.A., Webb, P., Griffiths, J.K. and Deckelbaum, R.J. (2014) Agriculture, nutrition, and health in global development: typology and metrics for integrated interventions and research. Annals of the New York Academy of Sciences 1331(1), 258-269.

MQSUN (2017) DFID's Aid Spending for Nutrition: 2015. Maximizing the Quality of Scaling Up Nutrition (MQSUN), Washington, DC.

New Alliance (2015) Commitments. New Alliance for Food Security and Nutrition. Available at: https:// new-alliance.org/commitments\#commitments_policy (accessed 9 April 2018).

Paarlberg, R. (2012) Impact Assessment: IFPRI 2020 Conference on 'Leveraging Agriculture for Improving Nutrition and Health'. IFPRI Impact Assessment Discussion Paper 34. International Food Policy Research Institute (IFPRI), Washington, DC.

Pinstrup-Andersen, P. (2013) Nutrition-sensitive food systems: from rhetoric to action. The Lancet 382 (9890), 375-376.

Republic of Uganda (2013) National Agriculture Policy. Ministry of Agriculture, Animal Industry, and Fisheries, Kampala.

Ruel, M. and Alderman, H. (2013) Nutrition-sensitive interventions and programmes: how can they help to accelerate progress in improving maternal and child nutrition? The Lancet 382 (9891), 536-551.

Ruel, M.T., Quisumbing, A.R. and Balagamwala, M. (2017) Nutrition-Sensitive Agriculture. What Have We Learned and Where Do We Go from Here? IFPRI Discussion Paper \#01861. International Food Policy Research Institute (IFPRI), Washington, DC. 
SUN (2015) The Contribution of Agriculture and Social Protection to Improving Nutrition. Scaling Up Nutrition in Practice No. 4. SUN Secretariat, Geneva.

Shahan, A.M. and Jahan, F. (2017) Opening the Policy Space: the Dynamics of Nutrition Policy Making in Bangladesh. Agropolis International, Global Support Facility for the National Information Platforms for Nutrition initiative, Montpellier, France.

Spielman, D.J. and Pandya-Lorch, R. (2009) Fifty years of progress. In: Spielman, D.J. and Pandya-Lorch, R. (eds) Millions Fed: Proven Successes in Agricultural Development. International Food Policy Research Institute (IFPRI), Washington, DC, pp. 1-18.

TANGO International (2015) Use of Research by International NGOs Working on Agriculture and Nutrition: current practices and opportunities for enhancing research uptake and impact. TANGO International, Tucson, Arizona.

Turner, R., Hawkes, C., Waage, J., Ferguson, E., Haseen, F. et al. (2013) Agriculture for improved nutrition: the current research landscape. Food Nutrition Bulletin 34, 369-377.

UNSCN, UN Environment, IUNS and WHO (2015) Sustainable Food Systems and Health - the convenient truth of addressing climate change while promoting health. United Nations System Standing Committee on Nutrition (UNSCN), c/o FAO, Rome. Available at: https://www.unscn.org/en/resource-center/UNSCNPublications?idnews $=1427 /$ (accessed 9 April 2018).

Webb, P. and Kennedy, E. (2014) Impacts of agriculture on nutrition: nature of the evidence and research gaps. Food and Nutrition Bulletin 35, 126-132.

Webb-Girard, A., Self, J.L., McAuliffe, C. and Olude, O. (2012) The effects of household food production strategies on the health and nutrition outcomes of women and young children: a systematic review. Paediatric and Perinatal Epidemiology 26 (suppl. 1), 205-222. Available at: http://www.ncbi.nlm.nih. gov/pubmed/22742612 (accessed 6 November 2012).

World Bank Group (2014) Learning from World Bank History: Agriculture and Food-Based Approaches for Addressing Malnutrition. Agriculture and Environmental Services Discussion Paper No. 10. World Bank, Washington, DC.

WHO (2017) Work Programme of the UN Decade of Action on Nutrition (2016-2025) - first draft. World Health Organization, Rome. Available at: http://www.who.int/nutrition/decade-of-action/draft_workprogramme doa_2016to2025.pdf (accessed 1 April 2018). 